\title{
A tecnologia como elemento transversal da cena
}

\author{
Technology as a transversal element into the scene
}

\author{
Camila Oliveira $^{1}$ \\ Christina Gontijo Fornaciari ${ }^{2}$
}

\section{RESUMO}

Este artigo propõe a mirada para a tecnologia como elemento transversal nas artes da cena (especificamente, a performance) por meio do mapeamento de eventos, espaços e artistas mineiros que fazem performance por distintas abordagens, porém atravessados pelo uso da tecnologia. Será identificada também a transversalidade da tecnologia no ambiente acadêmico das artes cênicas, mediante um levantamento qualitativo e quantitativo de sua inclusão em ementas ou projetos/linhas de pesquisa dos cursos de graduação em dança e teatro, em Minas Gerais.

Palavras-chave: Tecnologia. Performance. Academia.

\section{ABSTRACT}

This article proposes to look at technology as a transversal element in the performing arts (specifically, performance) through the mapping of events, spaces and artists from Minas Gerais that perform through different approaches, but crossed by the use of technology. It will also be identified the transversality of the technology in the academic environment of the Performing Arts, by means of a qualitative and quantitative survey of its inclusion in menus or projects / lines of research of the undergraduate courses in Dance and Theater, in Minas Gerais. Keywords: Performance. Technology. Academy.
1.

Bacharel e Licenciada em Dança pela Universidade Federal de Viçosa. ORCID: https://orcid.org/ oooo-0002-5698-5625 Contato: camilaoliveira.dan@gmail.com 2.

Professora do curso de Dança da Universidade Federal de Viçosa, Doutora em Artes Cênicas pela Universidade Federal da Bahia. ORCID: http://orcid.org/

oooo-0002-3551-4082

Contato:

christinafornaciari@gmail.com 
Este artigo visa mapear eventos, espaços e artistas mineiros que trabalham com performance e tecnologia, bem como pretende identificar a presença da temática tecnológica no ambiente acadêmico. Essa análise se mostra relevante tanto para acadêmicos quanto para artistas da cena, como uma forma de identificação da tecnologia como um elemento transversal na cena contemporânea, pela perspectiva de seus fazedores, pensadores e também produtores e fomentadores.

Pretende-se também, por meio desse elemento transversal, estabelecer um diálogo mais próximo entre os ambientes artístico e acadêmico, bem como entender a produção artística enquanto produção de conhecimento. Para isso, apresentamos inicialmente os fundamentos acerca da performance e da tecnologia, para mais adiante alinharmos esses fundamentos aos universos da formação e pesquisa nas artes cênicas, bem como da cena propriamente dita.

\section{Performance}

A palavra performance é normalmente utilizada na Língua Portuguesa como sinônimo de desempenho, seja artístico, esportivo, automobilístico, sexual ou em qualquer outra área. Mas também é conhecida como uma forma de arte, podendo ser ainda representada pela expressão performance art, como sugerido por José Mario Peixoto Santos (2008), para caracterizar ações do âmbito artístico. Enquanto arte, a performance foge de definições precisas e, justamente por isso, se torna complexa a definição de uma linguagem que se mostra tão ampla e multifacetada. Ainda de acordo com Santos (2008), "a performance é, por natureza, uma arte multidisciplinar, uma arte de fronteira, podendo ser também definida como uma arte híbrida”. Ao ampliar nosso conhecimento sobre essa linguagem podemos perceber que ela se encontra na fronteira entre as artes cênicas (dança e teatro), as artes visuais, a música e outras formas de arte. Na performance, elas se mesclam para formar "ações". A classificação é, portanto, aberta e inconstante, já que a prioridade é a abordagem de um tema e, para isso, o artista utiliza seu corpo, aliado a todas as ferramentas, materiais e linguagens disponíveis.

De acordo com Jorge Glusberg, em seu livro "A arte da performance" (2007), essa linguagem artística surge a partir de modificações nas formas do artista/performer se relacionar com seu trabalho e com o público, tendo seu início nos anos 1950. 
Mas ganha força na década de 1960, com ações do Judson Dance Group, que tem seu surgimento em 1962, formado por inúmeros artistas e

[...] cuja colaboração com os bailarinos e coreógrafos suscita criações que rompem a fronteira da dança - mesmo da dança moderna -, injetando novos e ricos elementos ao happening e delineando os contornos que caracterizarão a body art nos anos setenta. (GLUSBERG, 2007. p. 37).

Paralelo ao Judson Dance Group surgem outros movimentos como Fluxus, o grupo Gutai e ações individuais de artistas que compunham esses grupos e que vão inaugurar uma série de trabalhos que foram, posteriormente, considerados a origem da performance. De acordo com Santos (2008, p. 6), "[...] a arte da performance pode ser vista como um desdobramento da body art que é caracterizada pela forte referência ao corpo do artista, às roupas e objetos pessoais, aos fluidos e fragmentos corporais".

É importante refletir sobre o contexto social que abarca o auge da criação dessa linguagem. A sociedade e seus artistas, nos anos 1960 e 1970, estavam mergulhados em conflitos como a Guerra Fria e o Vietnã, que colocaram em voga discussões sobre corpo, gênero, classe e etnia. A performance, enquanto linguagem artística que leva para sua ação a vida do performer, torna presentes essas questões no fazer artístico. Neste contexto, ultrapassa as ações de body art, que exploravam as capacidades e limites do corpo "[...] - eliminando toda a exaltação à beleza a que ele foi elevado durante séculos pela literatura, pintura e escultura - para trazê-lo à sua verdadeira função: a de ser instrumento do homem, do qual, por sua vez, depende o homem" (GLUSBERG, 2007, p. 43). A performance se apresenta como uma ação mais ampla que, ainda de acordo com Glusberg (2007), incorpora outros aspectos individuais e sociais do artista e faz com que essas ações realizadas mostrem

[...] a dissolução do happening em modalidades retóricas mais sustentadas, nas quais a presença física do artista cresce de importância até se tornar a parte essencial do trabalho. Na verdade, essa transição é provocada pelos próprios artistas que trabalham com happening: eles advertem, porém, que não basta incorporar seres vivos ao environment - mesmo se um deles for o próprio artista - é necessário transformar o artista na própria obra. (GLUSBERG, 2007, p. 39).

Assim, podemos definir como uma das características da performance a presença do artista na obra, não como personagem, 
mas com sua história e suas realidades física, emocional, política e social em cena. Assim, a mídia principal do performer é o próprio corpo, tendo como ponto significativo na realização de suas ações a participação ativa do público. Fornaciari (2014, p. 28) complementa dizendo que "[...] o termo performance pode ser delimitado como uma arte que se vincula diretamente à experiência do expectador, tendo no performer um ativador ou propositor, cuja autoria é, acima de tudo, aberta e porosa".

Com a evolução da performance, vemos cada vez mais a exploração de conceitos como impermanência, aleatoriedade, acaso, ênfase no processo em detrimento da obra acabada, as relações entre arte e cotidiano e da desconstrução da divisão entre artista e público/plateia. Além disso, como afirma Fornaciari (2014, p. 13), ela acolhe diversos formatos e ocupa vários espaços, podendo ser programada ou acontecer sem aviso prévio, ocupar teatros, galerias de arte, casas, ruas, praças, metrô, internet; pode acontecer com roteiro fixo ou ser completamente espontânea e pode durar horas, anos, dias ou alguns segundos.

O que a define, portanto, não é seu formato, duração, ou o tema sobre o qual fala, mas sua capacidade de focar ação e a relação entre corpos, espaço, tempo, objetos. Os conceitos e temáticas que se deseja destacar acontecem por meio de ações que aparecem e desaparecem, são efêmeras. De acordo com Fornaciari (2014, p. 20), apenas os presentes durante sua realização podem fruir dessa arte, já que seus registros (como vídeos, fotografias entre outros) a transformam em outro tipo de obra.

No entanto, o que mais importa para muitos artistas performáticos não são as definições, os conceitos, muito menos as classificações e teorias relacionadas à arte da performance. A ação é o mais importante, o ato de elaborar, exibir e, sempre que possível ou necessário, "performar" (SANTOS, 2008).

Performance e tecnologia

Ao falarmos em tecnologia atualmente é fácil imaginar máquinas, equipamentos eletrônicos, computadores, aplicativos web e tantos outros acessórios facilmente disponíveis atualmente. Entretanto, se buscarmos essa palavra no dicionário Abbagnano (2007) veremos que tecnologia significa "Estudo dos processos técnicos de determinado ramo da produção industrial ou de vários ramos. O mesmo que técnica". Ao buscar técnica, por outro lado, encontramos: 
O sentido geral desse termo coincide com o sentido geral de arte (v.): compreende qualquer conjunto de regras aptas a dirigir eficazmente uma atividade qualquer. Nesse sentido, técnica não se distingue de arte, de ciência, nem de qualquer processo ou operação capazes de produzir um efeito qualquer: seu campo estende-se tanto quanto o de todas as atividades humanas. (ABBAGNANO, 2007).

Tecnologia, portanto, se mostra um termo amplo, capaz de ser interpretado de diversas formas por cada artista. Aqui, então, não utilizaremos uma definição rígida acerca do que é ou deixa de ser o uso de tecnologia em um trabalho artístico (cristalizar essa definição seria limitar as possibilidades artísticas existentes e ainda em exploração). Em nosso recorte nos guiamos por perguntas, como, por exemplo: essa performance existiria se não houvesse o uso de determinada tecnologia? Ela poderia ser concebida sem esse uso de tecnologia? Ela poderia ser exibida desta forma, sem o uso dessa determinada tecnologia?

Isso porque acreditamos que todo momento histórico é marcado pelos avanços inerentes a ele, e isso obviamente sempre se infiltra na arte. Nas palavras de Abiorana (2012), "novas manifestações artísticas emergem em cada momento histórico, marcadas por importantes avanços tecnológicos, tais como a invenção da fala, da escrita, da imprensa, da fotografia, do cinema e da web". E a performance não seria exceção.

Pensando na organização social em que vivemos atualmente, é fácil ver como a produção de conhecimento e tecnologia fez com que cada vez mais nossas atividades e relações cotidianas sejam mediadas por dispositivos eletrônicos e ambientes virtuais. Seja através de televisores, computadores, smartphones, internet com ou sem fio, e-commerce, nossa compreensão de presença vaza do mundo real ao virtual, sendo esses universos cada vez mais integrados, modificando nossas relações sociais, nossas rotinas e, em consequência, a exploração destas relações com o próprio corpo. Santos (2008) explora essa relação corpo tecnologia quando afirma que:

Este corpo atual, "transpassado por tecnologias", é, paradoxalmente, limitado pela intolerância característica de um poder global e hegemônico. Este corpo expressa a sociedade contemporânea em sua complexidade e fragmentação, onde signos culturais, identitários, políticos, coexistem sobre uma pele escamada e com grande potencial de transformação. Este é um corpo que concentra em si a capacidade de síntese de uma cultura predominantemente urbana, que ainda busca estabelecer uma relação mais equilibrada com o mundo artificial. 
Essa modificação, que atinge os artistas - e consequentemente a performance - começa a explorar pontes entre arte e tecnologia desde cedo. Já durante a revolução industrial, ações e objetos do cotidiano das fábricas eram introduzidos nas obras, aproximando-as cada vez mais do conhecimento e das inovações trazidas pela ciência.

A arte no século XX gerou uma grande multiplicidade de experimentações, testes de fronteiras e sobreposições de mídias, contextos, propostas e a tecnologia foi bem recebida nesse turbilhão de novas possibilidades. Curiosamente, enquanto a tecnologia se desenvolvia em meio a fios, máquinas e amplo aparato derivado de composições matemáticas e da física, a arte que surge do casamento arte-e-tecnologia é talvez a arte mais efêmera de todas: a arte do tempo (RUSH, 1999).

Assim, podemos ver inúmeros artistas que, a partir dos anos 1950, passam a experimentar relações com telas, vídeo, projeção de imagens, presença/comunicação virtual com o público, modificações corporais possibilitadas pelo avanço tecnológico da medicina, parcerias com a neurociência para provocar diferentes percepções corporais, entre tantas outras possibilidades que a parceria arte-tecnologia abre aos performers.

O corpo pode ser invadido, aumentado e expandido. Interfaces visuais, virtuais ou reais, possibilitam que o corpo atue em espaços eletrônicos, bem como permitem que espectadores conectados eletronicamente ao artista atuem sobre o seu corpo. O que se torna importante não é meramente a identidade do corpo, ou a ação realizada pelo artista, mas sua conectividade - não sua mobilidade ou sua localização, mas sua interface (FORNACIARI, 2014, p. 37).

Em comum, esses trabalhos têm suas performances realizadas com uma mescla de mídias, viabilizadas pelo uso da tecnologia, alterando as noções de espaço, tempo, presença e formas de comunicação com o público.

\section{O ambiente acadêmico e as artes cênicas}

As artes adentram a universidade aos poucos, mas têm ocupado cada vez mais espaço. Para que isso continue é necessário que cada vez mais pesquisas ocorram e, para isso, se faz necessário reconhecer qual a relação entre os artistas e o ambiente acadêmico. Partindo do histórico dessas relações, Cármen Arruda (2012) nos ajuda a esclarecer quando diz: 
É importante retomar a perspectiva histórica dessa questão: em 1971, no País, foi estabelecida a obrigatoriedade do ensino de artes na educação básica, mas a chamada reforma do ensino superior brasileiro, realizada em 1968 por meio da Lei 5.540 (Brasil, 1968), havia imposto restrições à habilitação de estudantes formados em conservatórios para o exercício da docência em música. A universidade tornou-se, assim, o acesso institucional à formação do artista com vistas à carreira docente.

Essa mudança no ensino, em conjunto com a obrigatoriedade da formação em arte, ocorre apenas no início dos anos 1970; portanto, essa relação entre artistas e universidades de maneira formal ainda é algo recente e em desenvolvimento dentro e fora das universidades. E, pelo longo histórico de diferenciação entre arte e conhecimento científico, ainda é necessário esclarecer essa relação, como nos afirma o Doutor em Comunicação e Semiótica Jorge de Albuquerque Vieira:

\begin{abstract}
A questão real é que a arte é uma forma de conhecimento, e todo conhecimento é função vital, todo conhecimento garante vida e complexidade. Desvalorizar o artístico é matar, em altos níveis de complexidade, nossa Humanidade. Insistimos aqui: a Arte é o tipo de conhecimento que explora as possibilidades do real. Não nos basta acreditar em uma certa realidade, temos que aprender os caminhos complexos para tentar atingi-la, e temos que fazer isso para sobreviver, não só em corpo, mas nos signos que já somos capazes de produzir e extrassomatizar para além das necessidades biológicas. (VIEIRA, 2006, apud MONTEIRO, 2014, p. 11).
\end{abstract}

A partir dessa relação da arte como forma de conhecimento, passível de criação a partir do diálogo com outras áreas, podemos reconhecer, portanto, na relação da arte com o conhecimento científico uma das formas para (re)pensar quais são os espaços ocupados pela arte no ambiente acadêmico atualmente e que relações são criadas entre artistas e educadores. É necessário pensar na formação em artes levando em conta uma problematização já discutida por Isabel Marques (2001) sobre ser docente e/ou artista, sobre como vamos atuar para que uma ação não exclua a outra, mas que se complementem. Isabel Marques traz em seu livro "Ensino de Dança Hoje: textos e contextos" (2001) um trecho que resume essa problemática:

[...] ao fazerem sua opção pelo ensino, escondem-se por trás do professor, pois acreditam existir uma ponte intransponível entre suas atividades artísticas e docentes. Para esses alunos, optar pela carreira de magistério corresponde predominantemente a 'sair do circuito', ou seja, a não atuar enquanto artista na sociedade. 
Assim, é necessário questionar quais as relações que os cursos de graduação em artes estabelecem entre conhecimento e fazer artístico. Monteiro estabelece esta relação, especificamente com relação aos cursos de dança, quando afirma que:

A universidade é lugar de referências, mas também - e principalmente - de debates. Os fluxos de informações que nela circulam são elementos que podem conduzir a uma dramaturgia crítica da dança. Ou seja, como agenciadora de questionamentos, ela tem função de formar artistas críticos que gerenciem seus trabalhos em função de debates que rondam/questionam a contemporaneidade (MONTEIRO, 2014, p. 14).

É de se pensar que as universidades incentivem essa formação e propiciem espaços de questionamento, debate e experimentação por meio da teoria e da prática artística, seja ela em uma linguagem específica ou de forma transdisciplinar e multifacetada. Ângela Maria Gonçalves Ferreira, bailarina e docente da Licenciatura em Dança na Universidade Cândido Mendes, corrobora com isso quando diz que

Torna-se interessante quando formas artísticas de conhecimento não se restringem a aplicações da teoria, mas sim começam a se desenvolver em formações híbridas de conhecimento, ou ainda, quando intervêm nos discursos teóricos, ou tenham um impacto sobre eles e, assim, contribuem para a construção de teorias. (FERREIRA, 2014, p. 24).

Por sua vez, a performance, enquanto linguagem artística, assim como artes visuais, teatro, dança, música, fotografia, cinema, e os vários híbridos entre essas linguagens, também pode ser vista enquanto geradora de conhecimento, podendo ser colocada paralelamente aos conhecimentos científicos, principalmente quando assumimos que ela adentra o ambiente acadêmico como área de pesquisa e formação profissional nas diversas graduações de artes existentes. Este espaço ocupado (ou não) pela performance foi objeto da pesquisa que resulta neste artigo.

\section{Metodologia}

A definição do método da pesquisa que aqui resulta partiu, primeiramente, do estudo da etimologia da palavra metodologia: Metá-hódos. Trata-se de um caminho (hódos) determinado pelas metas (metá) e assim, definimos utilizar a inversão desse 
caminho, ou seja, a cartografia. Como nos afirma Kastrup (2009, p.11), "a cartografia propõe uma reversão metodológica: transformar o méta-hódos em hódos-metá". Ou seja, primeiro o pesquisador se insere e habita aquele território, para então realizar o mapeamento a partir de seu ponto de vista.

Este mapeamento parte do conceito de que "a cartografia surge como um princípio do rizoma que atesta, no pensamento, sua força performática, sua pragmática um princípio inteiramente voltado para uma experiência ancorada no real" (DELEUZE, 1995, p. 21). Para tal estavam previstas três etapas.

A primeira (concomitante às outras etapas) consistiu em um levantamento bibliográfico para auxiliar a compreensão e discussão do nosso objeto, em revistas especializadas, artigos acadêmicos publicados em periódicos e bases de dados científicos e livros.

A segunda etapa se desenvolveu a partir da busca de espaços e eventos onde pudéssemos encontrar artistas/obras de performance atualmente em Minas Gerais. Utilizamos tanto da presença real, quanto de espaços virtuais (sites, blogs e páginas de redes sociais de artistas, grupos, coletivos, entre outros) para possibilitar a identificação destes artistas/obras/eventos. Páginas online - em especial a rede social Facebook - foram de suma importância para a realização dessa etapa.

Criamos uma fanpage para apresentar a nossa pesquisa, que foi usada para entrar em contato com alguns artistas e posteriormente para manter contato com os espaços e ter acesso a materiais como fotos, vídeos e outros registros das ações por eles realizadas.

A terceira etapa da pesquisa que aqui resulta envolveu entrevistas (pessoalmente ou via internet) semiestruturadas com os artistas selecionados e contato com as obras produzidas por eles. Essa etapa incluiu também o levantamento dos conteúdos sobre performance e tecnologia existentes nas Universidades Federais de Artes Cênicas (Teatro e Dança) no estado de Minas Gerais, a partir das ementas das disciplinas que os compõem.

A partir do material coletado, dos processos e produtos artísticos conhecidos, realizou-se uma análise interpretativa, fundamentada na inter-relação das informações recolhidas, para construção deste artigo.

Assim, a utilização da cartografia se justifica pela proximidade com os objetos da pesquisa, o que possibilitou lidar com a subjetividade desses artistas e suas obras de arte, interagir com essas pessoas e, assim, conseguir discutir as relações encontradas, não só entre os indivíduos e suas produções artísticas, mas das relações que se estabelecem entre eles, a sociedade e a vida acadêmica em especial. 
O método cartográfico é muito utilizado por artistas na Arte Contemporânea, na maneira como organizam e apresentam seus trabalhos, mostrando não só um objeto de pesquisa, mas também, o percurso, os seus desdobramentos e a possíveis redes que a ele se conectam. A cartografia organiza o processo, reorganizando as ideias, o pensamento do artista pesquisador (MOURA \& HERNANDEZ, s/ano, p. 2).

Após realizadas as entrevistas, foi conduzida uma análise interpretativa das informações adquiridas com os artistas, tendo como objetivo refletir sobre as relações entre a produção de performance mediada por tecnologia e o ambiente acadêmico. Vale ressaltar que entendemos esta pesquisa como análise inicial, que pretende incitar novos questionamentos acerca da tecnologia como atravessadora dessa forma de produção de arte e suas relações com o conhecimento científico.

\section{Discussão}

Fazendo a relação entre a performance tecnológica e o ambiente acadêmico, relembramos que a academia talvez seja um dos lugares de origem da experimentação, onde novas formas de fazer podem surgir. E, devido à característica experimental da performance, sua junção com o ambiente acadêmico fez muito sentido para nós, como aponta Jorge Glusberg:

A importância da performance pode ser sentida também pelo crescente número de artistas que se dedicam a essa disciplina experimental, e pela influência que essa arte exerce na renovação do teatro, da música e da dança (2007, p. 48).

Este trabalho, então, faz um levantamento primeiramente dos cursos de graduação em Universidades Federais de Artes Cênicas (Teatro e Dança) em Minas Gerais, analisando a existência ou não de conteúdos que abordam performance e tecnologia, partindo das informações disponíveis na internet sobre seus currículos, ementas de disciplinas obrigatórias e optativas, além de espaços vinculados aos cursos em questão como grupos de estudo e linhas de pesquisa assumidas pelas graduações em questão. Foram analisados os seguintes cursos:

- Artes Cênicas na Universidade Federal de Ouro Preto (UFOP);

- Dança na Universidade Federal de Minas Gerais (UFMG);

- Dança na Universidade Federal de Uberlândia (UFU);

- Dança na Universidade Federal de Viçosa (UFV); 
- Teatro na Universidade Federal de Minas Gerais (UFMG);

- Teatro na Universidade Federal de São João del-Rei (UFSJ);

- Teatro na Universidade Federal de Uberlândia (UFU).

Levando-se em consideração as disciplinas que abordam em seus objetivos e/ou conteúdos programáticos temas como: tecnologia, novas mídias, uso de vídeo para arte, performance, história da performance e criação de cenas com linguagem híbrida, sendo eles o tema principal ou complementar entre os assuntos abordados, foram encontradas 24 disciplinas que se encaixam no perfil. Com a análise dos conteúdos verifica-se que todos os cursos que integram a pesquisa possuem conteúdos em pelo menos uma das áreas, performance ou tecnologia, sejam elas abordadas como temas principais ou complementares durante as disciplinas. A existência desses espaços aponta um crescimento do desenvolvimento dessas linguagens e a importância que tem sido dada ao estudo destes temas para a formação dos artistas atuais. Apesar de não encontrar nenhum conteúdo ou espaço explicitamente que una performance e tecnologia, a existência de espaços que abordam os dois temas em separado ocorre em quatro dos sete cursos pesquisados, sendo eles:

- Dança da UFU, com duas disciplinas sobre performance e três sobre tecnologia;

- Dança da UFMG, com uma disciplina sobre performance e duas sobre tecnologia;

- Teatro da UFSJ, com uma disciplina sobre tecnologia e um grupo de estudos em performance;

- Artes Cênicas da UFOP, com uma disciplina sobre performance, uma linha de pesquisa em performance e um grupo de estudos em tecnologia.

Os outros três cursos apresentam conteúdos apenas sobre tecnologia, como é o caso do curso de Dança da UFV ou apenas sobre Performance, como os cursos de Teatro da UFU e UFMG.

O contato dos alunos com esses conteúdos, ainda que em separado, proporciona não apenas experiências sobre o tema, mas instiga curiosidade e possibilita o uso dessas linguagens como ferramentas para a experimentação de diferentes formas para se fazer arte.

Após a busca dos conteúdos dentro dos espaços de graduação, foi realizado ainda um levantamento de outros espaços para essa forma de arte. Assim, uma busca por artistas e locais de produção de performance e tecnologia foi feita através de redes sociais online, sites governamentais de fomento à arte, espaços físicos, festivais, coletivos e eventos em Minas Gerais. 
O primeiro passo foi a criação de uma fanpage na rede social Facebook que continha a descrição da proposta desta pesquisa e uma convocatória para os artistas que se identificassem com a proposta entrassem em contato. Esta página foi compartilhada entre grupos de artistas para divulgação da proposta e seleção de artistas que trabalhassem com performance e tecnologia em Minas Gerais, para compartilhamento de informações sobre seus trabalhos.

A partir do contato com essas pessoas, iniciamos a coleta de informações e a busca por outros espaços envolvidos com essas linguagens. Com isso, foram realizadas buscas na internet a partir de palavras-chave como "performance", "performance art", "arte e tecnologia", "novas mídias", "performance MG", tanto em sites governamentais - como o da Funarte e do MINC - como em redes sociais e apenas no Google. Através dessa busca foram encontrados 123 resultados entre artistas, espaços de performance, encontros, mostras, residências, grupos de discussão e outros formatos de eventos presenciais e/ou virtuais. Dentre os resultados encontrados, 43 tinham sede fora do Brasil - e não serão detalhados aqui - e 66 eram sediados no Brasil, sendo 13 deles em Minas Gerais.

Entre os treze resultados encontrados, temos três fanpages na rede social Facebook de compartilhamento de informações sobre eventos, cursos e ações em performance, sendo eles:

- Festival de Performance BH - com a última publicação feita em agosto de 2012, o grupo se refere ao evento que teve sua $2^{\mathrm{a}}$ edição realizada de 8 a 14 de agosto de 2011, visando proporcionar a troca de experiências entre artistas convidados, a capacitação de estudantes de arte, a divulgação de trabalhos de artistas locais e fomentar o desenvolvimento e a reflexão dessa linguagem artística que integra corpo, som, imagem e palavra. Ao todo, foram realizadas mais de 70 ações em diversos espaços da cidade de Belo Horizonte.

- Performance BH - com a última publicação feita em agosto de 2015, sem informações sobre seu responsável e/ou criador.

- Performance Urbana Nenhum dos Mundos - com a última publicação feita em setembro de 2016 e originado a partir do Festival Nenhum dos Mundos de Performance Urbana, realizado em Belo Horizonte, em 2014, pela Nenhum dos Mundos Produções.

Além dos espaços de compartilhamento, ainda foram encontradas outras duas fanpages na rede social Facebook e um evento, sendo elas: 
- Casa Perpendicular, um espaço em Belo Horizonte para residências artísticas, oficinas, encontros, etc. coordenada por Wagner Rossi Campos em Belo Horizonte.

- Cursos de Dança, Performance e Ensino. Um espaço online, criado em 2015 para divulgação de informações sobre a PósGraduação em Arte da Performance (MA) da PUC Minas, e ações realizadas vinculadas ao curso, sob coordenação de Paola Rettore.

- QI - Quartas de Improviso, compostas por uma série de eventos realizados semanalmente com organização de Henrique Iwao e Matthias Koole que convidam outros artistas para sessões de improviso em conjunto em Belo Horizonte, os eventos acontecem desde 2013.

Entre os resultados temos ainda dois blogs sobre eventos realizados em MG, sendo eles:

- FAC - Festival de Artes do Corpo, que contou com três edições, respectivamente nos anos de 2012, 2013 e 2014. O festival acontece em Juiz de Fora e está vinculado ao grupo de estudos da Universidade Federal de Juiz de Fora ILEA - Intervenções em Lugares, Espaços e Adjacências, criado em 2011.

- "Perfura: ateliê de performance", que se configura, de acordo com a descrição do blog, como um "espaço para compartilhamento de espaços e processos de pesquisa e criação na arte da ação, experimentação de procedimentos e realizações performáticas através de estratégias de acesso e formação articuladas a partir das atividades e vivências no ateliê. Com curadoria de Ana Luisa Santos, ativado por uma rede com mais de jo presenças."

- "Performance no Memorial", descrito no site como "em sintonia com as principais tendências da arte contemporânea, o Memorial Minas Gerais Vale lançou em 2013, um programa de performances, sob coordenação do artista plástico e performer Marco Paulo Rolla".

- Outra Presença, uma exposição realizada de 01 de novembro a 01 de dezembro de 2013, com a proposição de ativar a espacialidade do MAP - Museu de Arte da Pampulha na intenção de "[...] operar temporalidades em vários sentidos, como por exemplo, no sentido do passado, presente e futuro, ou na desaceleração do tempo virtual, no tempo presença viva determinada pela performance." (SANTOS et al., 2014, p. 10). 
E, para finalizar, temos ainda dois resultados de iniciativas independentes, sendo eles:

- MIP - Manifestação Internacional de Performance, que já teve três edições nos anos de 2003, 2009 e 2016, organizado em Belo Horizonte pelo CEIA - Centro de Experimentação e Informação de Arte, criado por Marcos Paulo Rolla e Marcos Hill em 2000.

- Vespa Víbice - Via de Experimento em Performance e Ação, encontrado como um perfil no "facebook" ele representa um espaço de criação de autoria coletiva que surgiu em 2014 em Belo Horizonte e se descreve como "um ajuntamento anamorfo [sic] de pessoas interessadas em investigar e disparar acontecimentos acerca do corpo ampliando cruzamentos nas diversas linguagens. Já realizamos encontros internacionais, aventuras, derivas, trabalho conceitual, publicação independente, infiltramos espaços, já participamos de festivais de vídeo pelo Brasil, nos juntamos, nos dissipamos, existimos".

Foram encontrados ainda nove espaços "não territoriais" e dois espaços diretamente ligados a graduações em artes. Os espaços aqui chamados de "não territoriais" consistem em espaços de compartilhamento de informações que existem apenas virtualmente, via grupos de Facebook, e não possuem uma sede física ou um vínculo territorial definido, reunindo artistas de toda parte interessados em enviar/receber/discutir informações sobre arte e performance. Esses grupos apontam para uma nova forma de compartilhamento, divulgação e troca de experiências entre artistas possibilitada pelas redes sociais.

Dois espaços diretamente ligados a educação em artes foram identificados: a fanpage "Cursos de Dança, Performance e Ensino", ligada à pós-graduação em Arte da Performance da PUC-Minas, e o blog sobre o "FAC - Festival de Artes do Corpo", vinculado ao grupo de estudos da Universidade Federal de Juiz de Fora ILEA Intervenções em Lugares, Espaços e Adjacências. O que reafirma, em concordância com as disciplinas já analisadas anteriormente, que o ambiente acadêmico se encontra perpassado pela performance e pela tecnologia, não só estudando sobre, mas também produzindo ações performáticas.

Apesar de todos os espaços encontrados terem, em seu histórico, trabalhos de performance e tecnologia, nenhum deles tem a tecnologia como seu objetivo principal ou exclusivo. Os assuntos permeiam os interesses dos grupos/eventos a cada momento, 
sem a obrigatoriedade do uso da tecnologia. O fato é que ela está sempre lá, como uma possível ferramenta, como uma presença transversal na cena.

Com o intuito de observar, na prática, como se dá essa transversalidade, entramos em contato e participamos (como pesquisadores-artistas) de dois eventos, interagindo com os artistas envolvidos, conhecendo e apreciando seus trabalhos, conversando pessoalmente e fruindo as obras, o que, na performance se faz extremamente necessário, uma vez que falar sobre ou ter acesso aos registros da obra não alcança a complexidade que é viver aquele momento único junto ao performer. Assim, ocorreram participações no Vespa $\mathrm{f}(\mathrm{x}) 2$ e QI087.

O Vespa $\mathrm{f}(\mathrm{x}) 2$, já em sua segunda edição, reuniu diversos performers de vários estados do Brasil em Belo Horizonte nos dias 20 e 21 de maio de 2016 para compartilhamento de trabalhos, em um total de 41 ações. Como dito, o evento não possui foco específico em trabalhos com tecnologia, mas abarca trabalhos com vários focos, desde experiências mais viscerais até experimentações tecnológicas, vídeo-arte e trabalhos transmitidos via web.

Entre todas as ações realizadas, identificamos 11 que foram atravessadas de forma explicita pela tecnologia. Além dos momentos de intervenção artística, o evento contou com encontros para socialização e conversas informais entre os artistas participantes e a alteração de diversas intervenções do local inicialmente planejado para o espaço da Funarte (Belo Horizonte), onde ocorria uma ocupação em protesto a divulgação do fechamento do MinC (Ministério da Cultura), que passaria a ser uma secretaria do Ministério da Educação. O contato entre performance, experimentação, ocupação de espaços para protesto político e contato direto de artistas com um público que habitava o espaço com outros objetivos que não a fruição de uma performance gerou atritos e diálogos muito enriquecedores sobre o quão híbrida e plural as ações dos performers podem ser. Outra questão que se confirmou foi a presença da tecnologia, não apenas nas ações assim planejadas, mas nos presentes durante a performance que assistiam, interagiam, tiravam fotos para suas redes sociais e faziam transmissões ao vivo para registrar o momento. Com isso, temos tanto entre os performers convidados como entre os espectadores presenças físicas e virtuais acontecendo de forma híbrida e quase indissociável.

Já a QI087, que foi a $87^{\mathrm{a}}$ edição das Quartas de Improviso, aconteceu em 28 de setembro de 2016 na galeria Ÿstilingue do Edifício Maletta, em Belo Horizonte. A proposta do evento é que seus organizadores, Henrique Iwao e Matthias Koole - ambos 
artistas com foco em música experimental - convidam a cada edição um outro artista para uma sessão de improviso que conta com tecnologia (programas de computadores) para criação e distorção de sons, além de apresentar propostas tecnológicas dos artistas convidados em algumas edições.

Na edição 87 a artista convidada foi Camila Oliveira, que realizou sua ação com foco na cena e nas relações com o espaço. A cena foi produzida a partir de criações sonoras improvisadas em conjunto com a proposta de intervenção dos/com os participantes e o espaço a partir de registros gráficos de memórias e sensações que passariam a ocupar e reorganizar o espaço. As relações criadas em tempo real com diversas tomadas de decisão que, por fim, criaram uma cena que agrupou todas as ações ali realizadas, geraram uma experiência única resultante da tomada de decisões dos três performers em cena e do público, que se tornou participante ativo à medida que reorganizava e acrescentava informações ao espaço da galeria. A proximidade física gerada pelo pouco espaço usado na performance contribuiu para o aumento de cruzamentos de informações entre todos os presentes, seja com os registros gráficos ou com a geração de sons, via equipamentos tecnológicos, instrumentos musicais, movimentos e manipulação de materiais.

O desenvolvimento da pesquisa e essas duas ações presenciadas possibilitaram perceber que performer que trabalha com tecnologia é uma definição que não descreve nenhum dos artistas identificados ao longo deste processo. O perfil dos artistas encontrados era híbrido, múltiplo e não poderia ser resumido nesses dois pontos apenas, apesar de a tecnologia estar presente em todas essas criações, seja no processo de criação, na ação apresentada ou nas formas de repercussão e divulgação destes trabalhos. Essas informações são reafirmadas pelos artistas Marcelo Kraizer e Henrique Iwao, que foram entrevistados para essa pesquisa.

Marcelo Kraiser se apresenta como um artista não especializado, trabalha com fotografia, desenho, arte sonora, construção de instrumentos sonoros, performance e poesia. Henrique Iwao se apresenta como intelectual e "artista"; trabalha com música experimental e afins, e assume um apego especial pela música, mas atua com performance à medida que seus trabalhos envolvem mais linguagens artísticas. Ambos vivem, atualmente, em Belo Horizonte-MG e trabalham com performance e produção de sons, cada um em sua especificidade.

As entrevistas foram voltadas para como eles realizam seus trabalhos e quais as relações criadas com a performance, o ambiente acadêmico e o atravessamento das tecnologias em suas 
ações. Uma das preocupações foi com relação ao reconhecimento desses artistas enquanto performers. Quando perguntados, as respostas possibilitaram perceber não apenas como se colocavam frente a isso, mas o que percebem enquanto performance. Iwao diz que:

Me reconheço (como performer). Embora eu ainda tenho um apego especial pela música - me considere músico etc, existem coisas que são muito melhor descritas como "performance". E então é possível deslocar um pouco não só o modo de atuação, mas algumas das preocupações. Ademais tem uma coisa: você começa a se relacionar com pessoas de formações e preocupações muito diferentes, o que é bom. E mesmo trabalhando muito com o som, começa a perceber como é possível ter outros tipos de relações com o som, que não são de músico. De outra forma, levar a sério uma atitude cotidiana, ou uma atitude absurda, é algo que eu identifico como próximo da performance. $\mathrm{E}$ a possibilidade de nomear como performance é um tipo de proteção - ajuda a valorizar, a justificar o tempo despendido.

Já Kraiser fala sobre:

Reconheço sim (enquanto performer). Embora não exista uma definição única de performance, entendo-a como exploração de relações entre arte e vida, arte e pensamento, arte e corpo, além de outras relações. A performance pode ter um grande componente improvisacional no qual o acaso comparece como risco e possibilidade de ruído e eventualmente transformação criativa e é isso que me interessa na mesma.

Essa relação com a performance pode ser encarada sob diversos olhares e reforçamos, portanto, a ideia de que criar uma definição cristalizada sobre o que é performance para apontar quem faz ou não faz torna-se uma postura que reduz a proposta desse fazer artístico multifacetado.

Quando perguntados sobre a relação com a tecnologia, ambos precisaram, antes de responder, definir o que entendem por tecnologia, para depois falar sobre o que usam em seus trabalhos. Os dois usam computadores, editores de áudio e vídeo, peças eletrônicas para criação de instrumentos e/ou peças a serem apresentadas, mas têm clareza em diferenciar tecnologia, tecnologia digital e tecnologia de ponta, como reforça Kraiser, ao dizer que "a tecnologia sempre esteve presente e não pode ser confundida com a última palavra em técnicas digitais ou outras do tipo". Quando perguntados sobre a influência disso na estética de seus trabalhos também concordam em dizer, como nos afirma Kraiser, que "elas não alteram a estética, fazem parte dela". Iwao ainda comple- 
menta: "Acho difícil de responder isso. Porque é como perguntar "e se"? E, do jeito que coloquei antes, não é tão possível tirar fora [sic] certos elementos. Acho que não tem 'versão acústico'".

Conversamos, por fim, sobre a relação com o acadêmico e o artístico em suas vidas e essas relações foram contrárias às expectativas da criação desta proposta. Ambos assumem uma relação que, ao mesmo tempo, é de proximidade e distância, pois os dois têm formação acadêmica e contato direto com esse ambiente, mas não relacionam isso diretamente com seus processos artísticos. Kraiser diz:

São muitíssimas coisas que compõem um trabalho, vão desde as experiências de vida até o impacto que causam outros artistas e suas obras. As leituras, as músicas, os filmes, os livros também. A formação acadêmica comparece como mais um desses fatores. Não gosto muito de falar em influências, pois dá a impressão que há uma neutralidade anterior que é modificada por elementos perturbadores de uma certa ordem anterior. Prefiro pensar em linhas e intercessores (num sentido deleuzeano do termo, ou seja, não necessariamente pessoas, mas tudo aquilo que impulsiona, modifica, choca e compõe as dinâmicas da vida, do pensamento, das maneiras de afetar e ser afetado na arte e fora dela).

Iwao olha para a questão por outro ângulo, e afirma:

Não acho estritamente importante. Tenho inclusive mais interesse por quem não passou por formação acadêmica. Por que? Bom, para variar. Existem meios em que soa quase necessário ter formação acadêmica, eu acho isso um pouco irritante. Eu acho triste o fato da universidade aparecer muitas vezes como um dever (você deve ir para a universidade) ou ainda a única opção interessante de integração e formação artística numa certa faixa etária. Depois que me formei na Unicamp, procurei sempre organizar eventos, encontros, seminários e revistas etc. fora do meio universitário (nem sempre consegui, as universidades podem ser parceiras importantes e interessantes). Não por ser contra ele, mas porque nele já existem coisas, e são meios institucionais - e isso acaba afetando os modos de circular e fazer. Eu tenho um lado bastante intelectual - de gostar de aglutinar pensamentos, colocações e questões ao redor das obras. Mas eu não vejo isso como algo que tenha uma relação direta com a universidade ou "o acadêmico".

Uma outra questão apontada durante a entrevista se mostrou relevante, relativa à compreensão de como fazer performance e como compartilhar esse conhecimento, em se tratando de uma linguagem artística difícil de se definir, que não tem locais determinados para acontecer, podendo ser realizada em diversos espaços, inclusive em espaços não especializados de arte, e em 
que seus realizadores estão envolvidos com diversas linguagens e interagindo com diferentes ambientes. Sobre isso, Iwao afirma:

\begin{abstract}
Uma coisa que percebi é que para aprender fazendo, em uma área, tanto a música experimental quanto a performance, em que não há carreira, você precisa criar uma comunidade. A partir daí as pessoas podem trocar entre si experiência, conhecimento e principalmente, afeto - do tipo "o que você faz é legal". É importante não estar sozinho no mundo. Então, uma parte dos meus esforços, desde o segundo ano na universidade até depois foi de ir criando a possibilidade de estar em comunidade.
\end{abstract}

É importante salientar que essas comunidades aqui analisadas são duas, a artística e a acadêmica, e que em ambas encontramos cruzamentos entre performance e tecnologia, seja nos cursos de graduação, em que encontramos pelo menos dois semestres de estudos sobre esses temas, como já visto anteriormente, seja nos eventos e espaços pesquisados em que, entre as ações de performance realizadas, encontramos números consideráveis de trabalhos com tecnologia.

A análise de dados nos mostra que todos os eventos de performance pesquisados, realizados em $\mathrm{BH}$ nos últimos oito anos, apresentaram performances utilizando tecnologia. Em alguns deles, $100 \%$ das performances apresentadas utilizam da tecnologia, como é o caso do evento "QI - Quartas de Improviso (87 das 87 apresentações envolvem tecnologia). Em outros casos, cerca de $50 \%$ das performances apresentadas envolvem tecnologia, como na exposição "Outra Presença - Museu de Arte da Pampulha" (49 das 75 performances apresentadas), e nos eventos da "Casa Perpendicular" (7 de 18 performances). Os demais, como o "Festival Nenhum dos Mundos de Performance", o "Vespa $\mathrm{f}(\mathrm{x}) 2$ ", o "Perfura: ateliê de performance", "Performance no Memorial - Memorial MG Vale" e a "MIP - Manifestação Internacional de Performance", apresentam pelo menos três obras de natureza tecnológica.

Não entraram nesta análise os eventos FAC - Festival de Artes do Corpo e Festival de Performance BH, devido à impossibilidade de acesso a informações que permitissem avaliar o número de ações realizadas e/ou o conteúdo dessas ações, seja por meio de textos, fotos ou vídeos, para a identificação da presença de tecnologia.

A partir dos resultados encontrados, é possível afirmar que a tecnologia está presente tanto em eventos, quanto em grande parte dos trabalhos neles apresentados, atingindo também contextos de formação artística.

Assim, a tecnologia está presente como elemento transversal 
na cena (artistas, espaços/eventos e academia), e isso não apenas expande as possibilidades de criação artística, como também gera redes de comunicação entre artistas e público, criando novas formas de colaboração, interação e compartilhamento de informações em arte.

Já com relação ao contexto acadêmico, a pesquisa nos mostra que o ensino de/em performance ainda é incipiente em cursos de graduação em teatro e dança de Minas Gerais. Além disso, em se tratando de performance tecnológica, constatamos que esse binômio é ainda mais embrionário, porém, em franca expansão. 


\section{REFERÊNCIAS BIBLIOGRÁFICAS}

ABBAGNANO, Nicola. Dicionário de Filosofia. Tradução da $1^{\mathrm{a}}$ Edição brasileira coordenada e revista por Alfredo Bossi; revisão da tradução e tradução dos novos textos Ivone Castilho Benedetti. $-5^{\text {a }}$ Ed. - São Paulo: Martins Fontes, 2007. ISBN 978-85-336-2356-9

ABIORANA, Dângela Nunes. Ciber: Cultura, Arte, Tecnologia In: V World Congress on Communication and Arts. Guimarães, PORTUGAL. April 15 - 18, 2012. p. 411-415.

ARRUDA, C. L. R.. As artes no ensino superior: entre a razão e a paixão. Pro-Posições vol.23 no.1. Campinas Jan./Apr. 2012. ISSN 1980-6248 Disponível em: <http://dx.doi.org/10.1590/S010373072012000100015> Acesso em: 15 de abril de 2016.

DELEUZE, Gilles e GUATTARI, Félix. Mil Platôs. v.1. Rio de Janeiro: Ed. 34 Letras, 1995. ISBN 85-85490-49-7

FERREIRA, Ângela Maria Gonçalves. Pesquisa em arte ou pesquisa com arte? Revista de Ciências Humanas, Viçosa, v. 14, n. 1, p. 19-26, jan./jun. 2014 ISSN 1519-1974

FORNACIARI, Christina Gontijo. CORPO POTÊNCIA: Política e Tecnologia na Performance Contemporânea. 2014. 251 f. Tese (Doutorado em Artes Cênicas) - Universidade Federal da Bahia, Bahia, 2014.

GLUSBERG, Jorge. A arte da performance. São Paulo: Perspectiva, 2007. ISBN 978-85-273-0675-1

KASTRUP, Virginia. PASSOS, Eduardo. ESCÓSSIA, Liliana. Pistas do método da cartografia: Pesquisa-intervenção e produção de subjetividade / orgs. Eduardo Passos, Virgínia Kastrup e Liliana da Escóssia. - Porto Alegre: Sulina, 2015. 207 p. ISBN 978-85-205-0530-4

MARQUES, Isabel A. Ensino de dança hoje: textos e contextos. 2. ed. - São Paulo: Cortez, 2001. ISBN 85-249-0717-7

TASSIS, Christiane. Memorial Minas Gerais Vale: o espaço vivo da cultura mineira ano 2013. Tradução de Sérgio Penna - Belo Horizonte: Rona Editora, 2014. 112p. ISBN 978-85-62805-19-6

MONTEIRO, Rodrigo dos Santos. Fios que se conectam: a dança e a universidade como agentes que (se) movem. Revista de Ciências Humanas, Viçosa, v. 14, n.1, p.9-18, jan./jun. 2014. ISS: 1519-1974 MOURA, C. B.; HERNANDEZ, A. Cartografia como método de pesquisa em arte. In: Seminário de História da Arte - Centro de Artes - UFPel, 2012. Disponível em:<http://periodicos.ufpel.edu. br/ojs2/index.php/Arte/article/viewFile/1694/1574>. Acesso em: O2 de novembro de 2015.

RUSH, Michael. Novas mídias na arte contemporânea / Michel Rush; tradução Cassia Maria Nasser; revisão da tradução Marylene 
Pinto Michael. - São Paulo: Martins Fontes, 2006. 225 p. ISBN 85-336-2313-5

SANTOS, Ana Luísa. ROLLA, Marco Paulo. LARSEN, Nathalia. Outra presença In: Outra Presença. Org. Museu de Arte da Pampulha - Belo Horizonte: Museu de Arte da Pampulha, 2014. 144p. ISBN 978-85-98964-15-7

SANTOS, José Mário Peixoto. Breve Histórico da "Performance Art" no Brasil e no Mundo. Revista Ohun, ano 4, n. 4, p. 1-32, dez 2008. ISSN 1807-595479

\section{REFERÊNCIAS ELETRÔNICAS}

Bacharelado em Dança da Universidade Federal de Viçosa. Disponível em: <http://www.catalogo.ufv.br/interno.php?curso $=$ DAN\&campus $=$ vicosa\&complemento $=$ BAC $>$ Acesso em: 06 mar. 2017.

Casa Perpendicular Disponível em: <https://www.facebook.com/ clubeperpendicular/?pnref=about.overview> Acesso em: o8 mar. 2017.

Cursos de Dança, Performance e Ensino Disponível em: <https:// www.facebook.com/CursosDancaPerformanceEnsino/?ref=br_ rs> Acesso em: 08 mar. 2017.

FAC - Festival de Artes do Corpo Disponível em: <http://www. artesdocorpo.com/p/i-fac.html> Acesso em: 06 mar. 2017.

Festival de Performance BH Disponível em: <https://www. facebook.com/Festival-de-Performance-BH-143190099086662/ ?ref=br_rs> Acesso em: 06 mar. 2017.

Funarte MG é palco de Festival de Performance Disponível em: <http://www.funarte.gov.br/funarte/funarte-mg-e-palco-de-festival-de-performance/\#ixzz4dCzbzGae> Acesso em: 31 mar. 2017.

Graduação em Dança da Universidade Federal de Uberlândia Disponível em: <http://www.iarte.ufu.br/dan\%C3\%A7a/fichas-dos-componentes-curriculares> Acesso em: 08 mar. 2017.

Graduação em Teatro da Universidade Federal de Minas Gerais. Disponível em: <https:/www.eba.ufmg.br/graduacao/teatro/ ?page_id=20> Acesso em: 08 mar. 2017.

Graduação em Teatro da Universidade Federal de São João del-Rei. Disponível em: <http://www.ufsj.edu.br/teatro/ementas_-_ planos_de_aula.php> Acesso em: 08 mar. 2017.

Graduação em Teatro da Universidade Federal de Uberlândia Disponível em: <http://www.iarte.ufu.br/teatro/fichas-dos-componentes-curriculares> Acesso em: 08 mar. 2017. 
Licenciatura em Artes Cênicas da Universidade Federal de Ouro Preto. Disponível em: <http://deart.ifac.ufop.br/> Acesso em: o8 mar. 2017.

Licenciatura em Dança da Universidade Federal de Minas Gerais. Disponível em: <https://www.eba.ufmg.br/graduacao/ Danca/Ementas.pdf >Acesso em: 08 mar. 2017.

Licenciatura em Dança da Universidade Federal de Viçosa. Disponível em: <http://www.catalogo.ufv.br/interno.php?curso=DAN\&campus=vicosa\&complemento $=$ LIC $>$ Acesso em: 08 mar. 2017. MIP - Manifestação Internacional de Performance. Disponível em: <http://www.ceiaart.com.br/br/mip3> Acesso em: 06 mar. 2017.

Performance BH Disponível em: <https://www.facebook.com/ PerformanceBh/?ref=br_rs > Acesso em: 06 mar. 2017.

Performance Urbana Disponível em: <https://www.facebook.com/ performanceurbana/?ref=br_rs > Acesso em: 06 mar. 2017.

Perfura Ateliê de Performance Disponível em: http://perfuraateliedeperformance.blogspot.com.br/ Acesso em: 28 mar. 2017.

Vespa Víbice Disponível em: <https://www.facebook.com/vespavibice> Acesso em: 06 mar. 2017. 